\title{
Optimization Research on College Students' Physical Health Monitoring Management
}

\author{
YU Zhen-peng \\ Anshan Normal University \\ Anshan Liaoning 114007, China
}

\begin{abstract}
Based on the implementation of the "standard", taking college students' physical health monitoring as the core, combined with the related monitoring theory, this paper analyzes the mechanism and operation mode of college students' physical health monitoring, excavates the existing problems and causes in the physique health monitoring mechanism, puts forward a proposal on health monitoring mechanism for the relevant management departments to develop and implement physical health policies, implementing of physical health monitoring and intervention to provide a reference and basis.
\end{abstract}

Keywords—College students; Physical health test; Management optimization

\section{INTRODUCTION}

In order to conscientiously improve the disadvantage of students' physique declining year by year, the Ministry of Education formally promulgated the National Students' Physical Health Standard (2014 Amendment) in July 2014. The document requires that all kinds of students at all levels in the country take part in physical fitness tests according to the requirements of the "Standards" and rank them according to the students' total physical health scores for the academic year[1]. However, the annual physical fitness test in our country consumes a lot of manpower and financial resources. There is still a big error in the reported data. There is also a big problem in the follow-up application of the test data, only to complete the test. After the test, the students' physique Health did not get any improvement. The reason for this is mainly related to the various problems we have in the body-based health monitoring mechanism and mode of operation. This paper mainly focuses on the present situation of students' physical health test management in our country, digs and analyzes the existing problems and causes, and puts forward some measurements to improve college students' physical health management.

\section{PRESENT SitUATION OF COLLEGE OF STUDENTS' PHYSIQUE HEALTH TEST MANAGEMENT}

\section{A. State attaching great importance}

Our government attaches great importance to students physical health. The Opinions of the General Office of the State Council on Strengthening Physical Education in Schools and Promoting the All-round Development of Students' Physical and Psychological Health (Guo Ban Fa [2016] No. 27) has made a comprehensive plan to promote the reform and development of school sports and to strengthen school physical education. It is necessary to pay attention to school physical education, strengthen the research on the reform of physical education, pay attention to the guiding function of school sports evaluation, and strengthen the leading role of school sports competition [2]. Especially in the past two years, the Central Committee of the Communist Party of China, the State Council, the Ministry of Education and other relevant ministries have successively promulgated documents or held meetings or started projects. They all closely follow a theme to strengthen school physical education and enhance their physical fitness. This is unprecedented in the history of school education in our country. This shows that our school physical education, young people's physical health there is the seriousness of the problem, but also shows the party and the state of great concern for this issue.

\section{B. Lacking of recognition of university degrees}

China's university leaders on the health of students generally test the work "to talk about the importance of doing it secondary, busy do not, usually not important, assessment is important" and has a long history [3]. What is more, when some colleges and universities report the test data of the National Students' Physique and Health Standard, some data are available to be revised so as to take advantage of superiority, inferiority and fraud. In 2014, the Ministry of Education conducted a review of the physical health test of college students across the country and found that there was a big gap between the data consistency and the result was shocking. In some provinces, the compliance rate was only $20 \%$. There was a big error in the data reported by a large number of schools. School organization work, but there are also data fraud reported by individual schools [4]. Students physical health test is not only relevant to the school sports department, but also require the faculty, logistics, hospitals and 
other departments working together to strengthen management and eliminate data fraud to ensure that the reported data can accurately reflect the true health of students.

\section{School testing management emphasis on testing and contempt intervention}

The physical education department of colleges and universities is the main management department that undertakes the students' physical health test. Normal colleges and universities have assigned special staff to take charge of this work and are responsible for the collection, reporting, analysis and feedback of the students' physical health test data every year. However, the implementation of "National Students "Physical Health Standard" in colleges and universities only includes the tests and data of students' constitutional health. The research on student's physical health only stays on the analysis and suggestion of some simple physical health status of students, there is no combination of "standard" implementation and follow-up service management for undergraduate physical fitness testing. At the same time, there is a lack of physical health risk factors intervention and feedback. The physical health data reported by the localities will be processed to provide corresponding physical and health information for individual students and schools. At the same time, targeted sports prescriptions will be provided according to the students' physical health. However, it is a question worth pondering whether the "standard" can serve as an educational measure, an incentive measure, or a constraint measure to achieve the desired effect. Therefore, it is essential that the close link between feedback and intervention in the implementation of "Standards" be necessary.

\section{Problems Existing In Students' Physical Health TEST MANAGEMENT}

\section{A. Tester attitude not correct}

Through surveys, some schools did not put promotional mobilization, staffing, equipment protection, testing procedures and other aspects of the arrangements in place, there are some not fine functional departments division of responsibility which is unknown, it is hard to effectively start physical monitoring. Participate in the test of physical education teachers do not know the place, the existence of the annual test to cope with behavior, coupled with many teachers are not too familiar with the test requirements and standards, the test is not positive, or even completely passed to the students test, students participate in the test also One can imagine. Test data accuracy greatly reduced, and even students to help students test cheating, fraud behavior, the impact of subsequent data analysis.

\section{B. Participation in test preparation for students still needed to be strengthened}

Students Physical Health Test Arrangements require students to do their best to complete the physical test project. However, since schools did not follow the MOE's request to strengthen the follow-up management and application of the students' physical health data in the implementation of the "Standards," many teaching units did not rely on the excellent physical fitness of students at the year-end, good, middle and qualified grades, so students do not attach importance to physical health testing. The main problems are as follows: Firstly, the purpose of the students participating in the test is not clear. Students cannot comprehend the importance and necessity of the physical test. They have the mentality to deal with the physical test, and the enthusiasm is not enough. Secondly, students lack of test preparation, a considerable number of students in the test wearing jeans, shoes and other unworthy of the test clothing, we surveyed that almost every university testing process exists in the phenomenon of nonstandard clothing. Thirdly, students did not fully warm up before the test. Many colleges and universities organize students' physical health test, there is no preparation for activities, brought out from the classroom that is, test or preparation for the activities in the form of prone to sports injuries and even potential safety problems.

\section{Instrument quality problems make testing difficult}

On the one hand, some colleges and universities in the test equipment because of long-term use, has been seriously aging and damage, and the lack of professional maintenance personnel care, resulting in the instrument often appears in the test inaccurate, failure phenomenon; on the other hand, some colleges and universities due to Insufficient funds are invested in the physical fitness test, so that the purchased test instruments are still purely manual operations, resulting in a large error in the test data. This is a test issue due to instrument problems. However, the school did not have a dedicated institution and a comprehensive program to deal with these issues, which made the problem more and more serious.

\section{Individual test items not standardized}

Student physical health test is divided into three categories: body shape, body function and physical fitness. For each project test, the Ministry of Education has issued a special test requirements and specifications. However, participating testers have a general understanding of test standards and specifications, leading to such problems when testing projects. For example: in the seat body flexion project testing process, the test action is not standardized, and some students did not take off your shoes, and some with one hand to promote the cursor test, there are test students have legs bent, followed by someone to help; Pull up equipment does not meet the test requirements, horizontal bar height is too high, the student's chin was significantly lower than the height of the horizontal bar, the test arm is not fully extended down; test sit-ups not standardized enough, students leg angle Large; test height, the students wear shoes test, poor test norms, resulting in greatly reduced the accuracy of test data. 
IV. Optimization of Students' Physical Health Test MANAGEMENT

\section{A. School leaders attaching importance to students' physical health testing}

Schools should attach great importance to students' physical health test work, set up by the head of the school, and with the Office of Academic Affairs (Office of Political Education), General Affairs Office, Department of Sports, Department of Health and other departments responsible for the formation of the students' health examination leading group. To regularly hold a group meeting of the Leading Group for Students' Physical Health Tests, earnestly implement the work responsibilities, configure and inspect the facilities and equipment required by the body side, and supervise and inspect all the preparatory work before the test. Screening of students who cannot participate in the test due to illness determines the samples of the students under test. Physical education teachers, school doctors, counselors and teachers in charge of undergraduate departments should do a good job of testing students' ideological mobilization and cooperating with the inspection team to do on-the-spot organization and testing work. Doing a good job in front of the test site, after-work logistics support personnel deployment and curriculum adjustment and other work. Schools should strictly implement the system of students' physical health work, strengthen the management of students' physical health monitoring, ensure accuracy when collecting students' physical health data, and timely upload students' physical health data to the Ministry of Education's data management center to enable students to Know your own body-side scores after testing.

\section{B. Physical testing time needs reasonable adjustment}

Physical fitness test students generally use centralized testing, centralized testing organizations and extracurricular tests, most of the schools use it in-class testing. As school physical education teachers have more teaching hours, if extracurricular testing is adopted, extra pressure will be added to the teachers to increase their work load. Students should be included in the workload of teachers according to the actual situation, and their salaries should be increased accordingly. Dispatch professionals to test the management mode, to solve this problem need all departments through unified research, put forward a reasonable implementation plan.

\section{Strengthen the "standard" evaluation results feedback and intervention links}

The implementation of the Standard has always emphasized the combination of evaluation feedback and intervention, but the link is often disjointed. Students only participate in the physical examination and do not know what to do next after obtaining the physical health test data. Although the physical education teacher can exercise according to the overall evaluation and guidance of the students, due to the lack of feedback and intervention in the "standard" Training project teachers are also relatively dazed. Therefore, it is an indispensable link to strengthen the evaluation of student's physical health test, the information feedback of the intervention function and the warning of early warning mechanism. The construction of students' constitutional health warning not only possesses the evaluation function of physical fitness test, but also can feedback students' comprehensive physical health information for students and physical education teachers. Feedback on students' creates a sense of urgency on the psychology level, urges the student to reevaluate the results of physical health evaluation, and then produces the corresponding physical activity. Early warning stepped up interventions so as to make the "standard" evaluation of performance feedback and intervention more complete.

\section{Establish reward and punishment mechanisms to enhance teachers' enthusiasm.}

All colleges and universities must implement the rewards and penalties for physical fitness testing in accordance with the policy. For teachers, especially physical education teachers, academic staff, and other staff who work outside the working hours, they must implement their overtime treatment and reduce their workload as much as possible so as to mobilize the enthusiasm of staff in all departments. At the same time, we must make use of rewards and penalties and strive to improve the testing skills and sense of responsibility of all staff to minimize human errors and errors.

\section{E. Correct students' attitudes toward physical fitness test}

Through the survey, it suggests that the current attitude of college students to the physical test is more negative. There are many reasons for this. There are two main reasons. First, students do not have a deep understanding of the purpose of the test. Some students do not even know the purpose of the test. Second, the test results are not linked to the usual physical education results, resulting in some students' perfunctory thing. In view of the above two situations, we should enlarge the explanation of the importance of the physique test purpose and the national requirement for student physique test, arouse students' interest in physical health test, and require each teaching unit to appraise the end of the year. When strict implementation of the "standard" requirement, the students physical health fail to excellence, forbid evaluation, evaluation and scholarship, only the effective implementation of this system down, I believe students' health testing will be acquired more and more students' attention so as to actively participate in physical activity.

\section{CONCLUSION}

In short, the development of the physical fitness test fully reflects the country's emphasis on the physical quality of college students. Therefore, the relevant competent authorities and institutions of higher learning must, on the one hand, do a good job of propaganda and education in the early stage and work out test plan which is practical feasible. Simultaneously, detailed analysis of the acquired physical data, and then feedback. On the other hand, colleges and universities should formulate corresponding exercise prescriptions according to the feedback of students' physical conditions, so that students can take the initiative to participate in physical fitness, thereby improving their health level. 


\section{REFERENCES}

[1] YOU Yun-qi.A comparison between and an analysis of test indexes specified in the National Student Physical Health Standard before and after adjustment [J]. Journal of Physical Education, 2013, 20(4):97-99.

[2] ZHANG Zong-guo.The Subjective and Objective Analysis of National Student Physical Health Standard [J]. China Sport Science, 2009, 29(9):88-90.

[3] ZHEN Zhi-ping,MAO Zhen-ming.Research on the Structure and Change of National Student' s Physical Fitness and Health Standards Index System [J]. Journal of Xi'An Physical Education University, 2008, 25(2):1-9.

[4] DAI Xia, ZHU Lin,XIE Hong-guang.Reflection and Optimization on evaluation Efficiency of National Student Physical Health StandardConstruction on Physical Fitness Early Warning System of College Student [J]. China Sport Science and Technology, 2012,48 (3):75-81. 